Nikkoh P. Muñoz, MD

Adrian F. Fernando, MD

Samantha S. Castañeda, MD ${ }^{1,2}$

Department of Otorhinolaryngology

Head and Neck Surgery'

The Medical City

Ateneo School of Medicine and Public Health ${ }^{2}$
Correspondence: Dr. Adrian F. Fernando

Department of Otorhinolaryngology

Head and Neck Surgery

The Medical City

Ortigas Avenue, Pasig City 1600

Philippines

Phone: (632) 6356789 local 6250

Fax: (632) 6873349

Email: ent@medicalcity.com.ph

The authors declared that this represents original material that is not being considered for publication or has not been published or accepted for publication elsewhere in full or in part, in print or electronic media; that the manuscript has been read and approved by the authors, that the requirements for authorship have been met by the authors, and that the authors believe that the manuscript represents honest work.

Disclosures: The authors signed disclosures that there are no financial or other (including personal) relationships, intellectual passion, political or religious beliefs, and institutional affiliations that might lead to a conflict of interest.

\section{$\Leftrightarrow(1) \Theta$}

Creative Commons (CC BY-NC-ND 4.0)

Attribution - NonCommercial - NoDerivatives 4.0 International

\title{
Fibular Dimensions for Mandibular Reconstruction among Filipinos
}

\begin{abstract} thickness) of the Filipino fibula are ideal for mandibular reconstruction.

\section{Methods:}

$\begin{array}{ll}\text { Design: } & \text { Cross-Sectional Study } \\ \text { Setting: } & \text { Anatomy dissection laboratory } \\ \text { Participants: } & 40 \text { fibulas from } 20 \text { adult cadavers }\end{array}$
\end{abstract}

Objective: To determine if the anatomic dimensions (length, cross-sectional width, cortical

Results: Morphometric examination showed the mean length of the harvested fibulas was 33.5 $\mathrm{cm}$. The mean horizontal (a-d) and vertical (b-c) widths of the proximal cross-section (point B) were $15.1 \pm 0.28 \mathrm{~mm}$ and $9.9 \pm 0.15 \mathrm{~mm}$ respectively. The mean horizontal (a-d) and vertical (b-c) widths of the distal cross-section (point D) were $15.4 \pm 0.24 \mathrm{~mm}$ and $10.3 \pm 0.49 \mathrm{~mm}$, respectively. The mean cortical thickness of the anterior (a), lateral (b), posterior (c) and medial (d) aspects of the proximal cross-section (point B) were $5.2 \pm 0.1 \mathrm{~mm}, 3.2 \pm 0.04 \mathrm{~mm}, 3.6 \pm 0.01 \mathrm{~mm}$, and $2.9 \pm$ $0.06 \mathrm{~mm}$, respectively. The mean cortical thickness of the anterior (a), lateral (b), posterior (c) and medial (d) aspects of the distal cross-section (point D) were $5.1 \pm 0.21 \mathrm{~mm}, 3.1 \pm 0.11 \mathrm{~mm}, 3.5 \pm$ $0.04 \mathrm{~mm}$, and $2.9 \pm 0.09 \mathrm{~mm}$, respectively.

Conclusion: Our findings show that the Filipino fibulas studied have dimensions that are ideal for mandibular reconstruction.

Keywords: Mandibular reconstruction, Fibula, Free Flaps, Fibular bone dimensions, Filipino

Over the past years, the fibular free flap has been considered the workhorse for mandibular reconstruction, having all the ideal features of adequate length, width, bone quantity and quality, and good success rate. ' In the Philippines, the fibular free flap has been previously described for head and neck reconstruction particularly for segmental mandibular defects and as a condylar autograft since 2005.2 Although great success has been encountered locally in terms of its survival, evaluation of its dimensions especially for dental restoration remains a challenge. 


\section{ORIGINAL ARTICLES}

To the best of our knowledge, based on a search of MEDLINE PubMed, WPRIM and Google Scholar using the keywords "mandibular reconstruction," "fibula," "free flap/s," and "fibular bone dimensions," data on the anatomic dimensions of the Filipino fibula has not yet been published to show if it meets ideal dimensions for mandibular reconstruction.

This study aims to determine the suitability of anatomic dimensions of harvested fibulae for mandibular reconstruction in Filipinos in terms of length $(\mathrm{cm})$ from fibular head to the lateral malleolus, cross-sectional width $(\mathrm{mm})$ along pre-determined segments and cross-sectional cortical bone thickness $(\mathrm{mm})$ along pre-determined segments.

\section{METHODS}

With Institutional Review Board approval, 40 fibulas of 20 formalinpreserved cadavers consisting of 12 males and 8 females located in the Anatomy Dissection Laboratory of the Ateneo School of Medicine and Public Health were harvested and measured. The number of available cadavers determined our sample size.

\section{Measurement of Fibular Length}

The fibulas were exposed along their length. For each fibula, the apex of the fibular head and apical margin of the lateral malleolus were referred to as ' $A$ ' and ' $E$ ', respectively. (Figure 1) The segment A- $E$ was divided into 4 segments. Point ' $C$ ' was midline and point ' $B$ ' and ' $D$ ' were marked $4 \mathrm{~cm}$ above and below point ' $C$ ' corresponding to the standard osteotomy sites in harvesting the fibula for free tissue

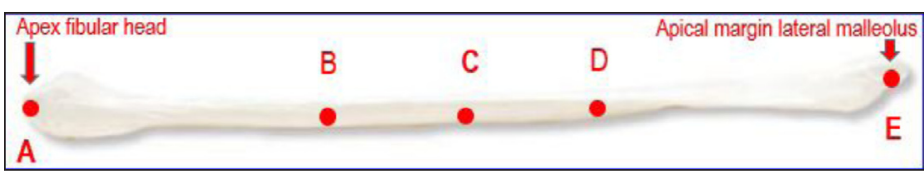

Figure 1. Transverse view of fibula showing segments used as reference

transfer. Measurements were sequentially obtained by two separate observers using a single soft tape measure (TR-13W Tailor's Tape, The Perfect Measuring Tape Company, Portland, OR, USA) and recorded in millimeters. A single recorded discrepancy above $10 \mathrm{~mm}$ was verified by re-measurement and consensus before recorded measurements were averaged and tabulated.

\section{Measurement of Cross-Sectional Width}

Osteotomies were performed on each fibula using a single oscillating saw (Mopec Autopsy Saw, Stryker', MI, USA) at points 'B' and ' $D$ ' corresponding to the actual osteotomy sites for fibular harvesting. The cross section of the segmentally osteotomized fibula were marked with points " $a$ ", " $b$ ", and "c" referred respectively as its anterior margin, medial crest and lateral margins. (Figure 2) The mid portion from points " $b$ " and " $c$ " was marked as point " $d$ ". The distance between points " $a$ " and " $d$ " was used to measure the vertical width of the fibular cross section while the distance from points "b" and "c" was used to measure its horizontal width. Measurements of cross-sectional width were sequentially obtained by two separate observers using a single 3.5" Castroviejo caliper (Braun - Aesculap Inc., PA, USA) and recorded in millimeters, averaged and tabulated.

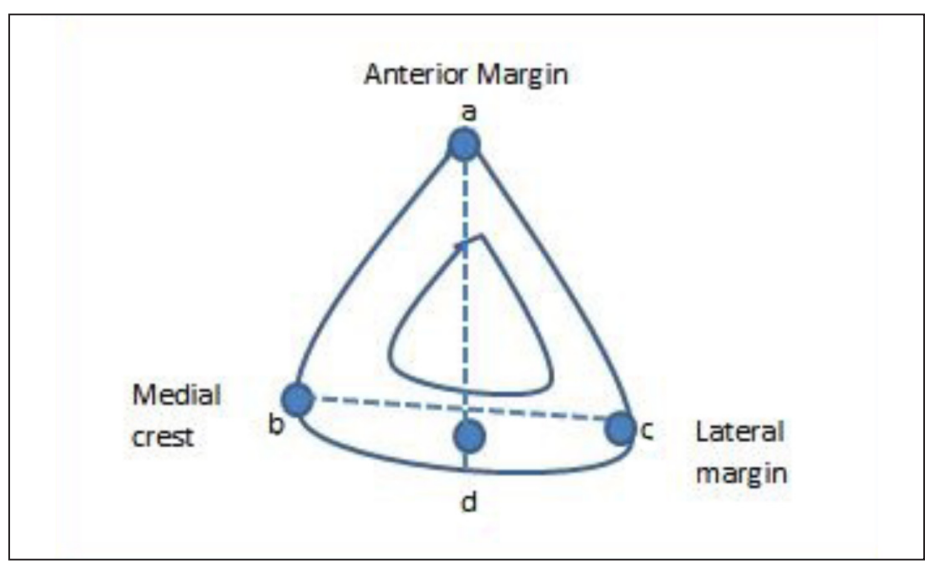

Figure 2. Model showing how cross-sectional width was determined

\section{Measurement of Cross-Sectional Cortical Bone Thickness}

At points $B$ and $D$ of each fibular segment, cortical bone thickness was sequentially measured by two separate observers using the same caliper at its anterior, lateral, posterior and medial aspects that were respectively marked as points [a], [b], [c], and [d]. (Figure 3)

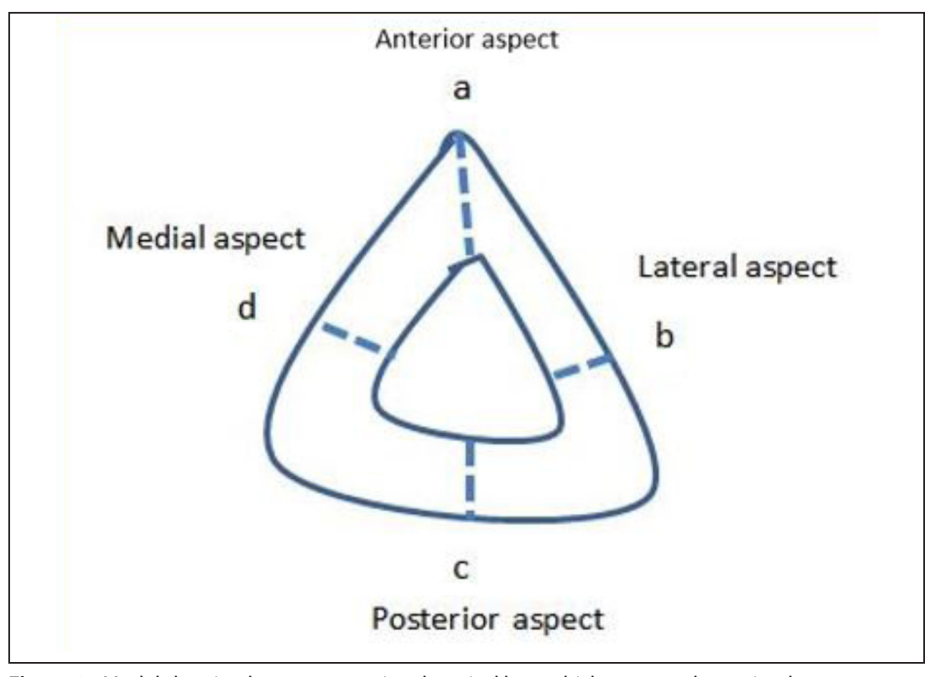

Figure 3. Model showing how cross-sectional cortical bone thickness was determined 


\section{Statistical Analysis}

Each distance was separately measured by 2 observers and encoded on MS Excel 2010 (Microsoft Corporation, Redwood WA, USA) for statistical data analysis using percentages, means and standard deviation. Discrepancies in measurements obtained by the two observers were insignificant (sub-centimeter) and simply averaged, except for the previously mentioned readings of fibular length of $>10$ $\mathrm{mm}$ that were re-measured to obtain a consensus.

\section{RESULTS}

Forty fibulas were successfully harvested and measured from 20 cadavers, of which there were 12 males (60\%) and 8 females (40\%) with a 3:2 male to female ratio.

\section{Fibular length and cross-sectional width at various segments}

The mean length of the harvested fibulas was $33.5 \mathrm{~cm}$. The mean horizontal (a-d) and vertical (b-c) widths of the proximal cross-section (point B) were $15.1 \pm 0.28 \mathrm{~mm}$ and $9.9 \pm 0.15 \mathrm{~mm}$, respectively. The mean horizontal (a-d) and vertical (b-c) widths of the distal crosssection (point D) were $15.4 \pm 0.24 \mathrm{~mm}$ and $10.3 \pm 0.49 \mathrm{~mm}$, respectively. (Figure 2)

\section{Thickness of Cortical Bone in Various Cross-Sectional Levels}

The mean cortical thickness of the anterior (a), lateral (b), posterior (c) and medial (d) aspects of the proximal cross-section (point B) were $5.2 \pm 0.1 \mathrm{~mm}, 3.2 \pm 0.04 \mathrm{~mm}, 3.6 \pm 0.01 \mathrm{~mm}$, and $2.9 \pm 0.06 \mathrm{~mm}$ respectively. The mean cortical thickness of the anterior (a), lateral (b), posterior (c) and medial (d) aspects of the distal cross-section (point $\mathrm{D}$ ) were $5.1 \pm 0.21 \mathrm{~mm}, 3.1 \pm 0.11 \mathrm{~mm}, 3.5 \pm 0.04 \mathrm{~mm}$, and $2.9 \pm 0.09 \mathrm{~mm}$, respectively. (Figure 3)

\section{DISCUSSION}

The osteocutaneous fibula free flap (OFFF) presents numerous advantages. The bony architecture is similar to that of the mandible, which on cross section shows a marble-like bone structure of thick compact layer giving an excellent anchorage for dental implants unlike iliac crest or scapula. ${ }^{3}$ The fibula also shows similarity to mandibular width and shape, and this also facilitates the insertion of dental implants. A study by Huryn et al. ${ }^{4}$ showed that fibula free flaps behave like an edentulous mandible. Thus, osseointegration can generally be expected. The grafts can easily be adjusted to the curvature of the mandible using osteotomy or the intersection technique. Owing to its extensive vascular network, the diaphysis of the fibula can be osteotomized into different segments without danger of necrosis.
Germain et al. ${ }^{5}$ reported that the fibula can provide up to $25 \mathrm{~cm}$ of bone for harvesting and it is necessary to preserve $6-7 \mathrm{~cm}$ of bone distally and proximally to maintain the integrity of the knee and ankle joint. Uchiyama et al. ${ }^{6}$ showed that it is necessary to preserve at least $6 \mathrm{~cm}$ of bone and that the distal fibula is responsible for stabilizing the ankle mortise during external rotation and inversion.

The fibula is a long thin non weight-bearing bone of the lower extremity. Frodel et al.' measured the height and weight of the fibula and the cortical thickness in transverse cross sections. It is one of the strongest bones available for transfer due to its tubular shape with thick cortical bone around the entire circumference. ${ }^{?}$

Analysis of our data suggests that the Filipino fibulas sampled have adequate length for mandibular reconstruction. The average length was noted to be $33.5 \mathrm{~cm}$. Sparing the necessary $6 \mathrm{~cm}$ (proximally and distally) to retain stability of the knee and ankle joint would still leave $21.5 \mathrm{~cm}$ of bone for mandibular reconstruction. A study by Apinhasmit et al. ${ }^{8}$ showed mean total fibular length and mean length of harvested fibulae were $34.2+/-2.3 \mathrm{~cm}$ and $18.2+/-2.3 \mathrm{~cm}$, respectively. A harvested fibula of 16 to $20 \mathrm{~cm}$ in length is sufficient to provide bone for reconstructing mandible defects. ${ }^{8}$

The fibulas were also noted to have a cross-sectional width of no less than $8 \mathrm{~mm}$ with the greatest diameter at segment a-d $(15.4 \mathrm{~mm})$. This was consistent with the study by Matsuura et al., ${ }^{9}$ where segment a-d was the longest in cross sections at $C, D$ and $E$. The a-d segment or the anterior margin of the fibula is often used to reconstruct the alveolar crest and the lateral surface of the fibula or the b-c segment is used to reconstruct the labiobuccal aspect. These findings should be useful for mandibular reconstruction.

In our study, the greatest cortical thickness was noted to be $6.5 \mathrm{~mm}$ with a mean of $5.2 \mathrm{~mm}$ at point a. This is again consistent with the study of Matsuura et al. ${ }^{9}$ which showed the greatest cortical thickness at apex a $(4.1 \mathrm{~mm})$. This is useful for osseointegrated implants, considering that osseointegrated implants have a width of $4 \mathrm{~mm}$, the fibula then has adequate cortical bone to surround the implant for better stability and thus success of the osseointegration. ${ }^{10}$

The use of osseointegrated implants restores both function and aesthetics. According to Anne-Gaelle et al. ${ }^{11}$ the success rate for osteointegration ranges from $86 \%$ to $99 \%$. Mandibular reconstruction by microvascular fibula free flap has dramatically improved the quality of life of patients treated by surgery.

The OFFF has its limitations. Because of its limited height (rarely more than $15 \mathrm{~mm}$ ) compared with the height of the mandible, vertical distance between the reconstructed segment and the occlusal plane can be substantial. To address this, Choo-Lee et al. ${ }^{12}$ showed that vertical 


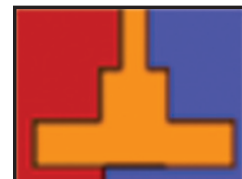

ORIGINAL ARTICLES

PJOAKS

Philippine Journal Of Otolaryngology-Head And Neck Surgery

VOL. 32 No. 1 JANUARY - JUNE 2017

distraction osteogenesis of free vascularized flaps is a reliable technique that optimizes implant positioning for ideal prosthetic rehabilitation, after mandibular reconstruction following tumor surgery.

Despite the sample size limitation imposed by the availability of cadavers, our study shows that the anatomic dimensions (length, cross-sectional width, cortical thickness) of the Filipino fibulas studied are sufficient for mandibular reconstruction. However, the sample of cadavers dissected may not be representative of the larger Filipino population, limiting the generalizability of our findings. Subsequent studies that are more representative may be more generalizable.

REFERENCES

1. Akheel M, Tomar SS, Bhargava A. Vascularized Free Fibula Flap for Reconstruction of Mandibular Defects. J Surg. Special Issue: Craniofacial Surgery. 2014 Dec; 2(6-1): 1-5. DOI: 10.11648/j. js.s.2014020601.11.

2. Yao M, Castaneda S, David J, Alonzo D. Condylar Autograft with Fibular Free Flap for Mandibular Reconstruction. Philipp J Otolaryngol Head Neck Surg. 2005; 20 (1-2): 31-38.

3. Stoll P. Indications and technical considerations of different fibula grafts. In: Greenberg AM Prein J (editors). Craniomaxillofacial reconstructive and corrective bone surgery: Principles of internal fixation using the AO/ASIF technique. NY: Springer-Verlag; 2002. 327-334.

4. Huryn JM, Zlotolow JM, Piro JD, Lenchewski E. Osseointegrated implants in microvascular fibula free flap reconstructed mandible. J Prosthet Dent. 1993;70:443. PMID: 8254548.

5. Germain MA, Gomez NG, Demers G, Hureau J. Anatomic basis of mandibular reconstruction by free vascularized fibula graft. Surg Radiol Anat 1993;15:213-214. PMID: 8235966.

6. Uchiyama E, Suzuki D, Kura H, Yamashita T, Murakami G. Distal fibular length needed for ankle stability. Foot Ankle Int. 2006 Mar; 27(3): 185-189. DOI: 10.1177/107110070602700306; PMID: 16539900.

7. Frodel JL Jr, Funk GF, Capper DT, Fridrich KL, Blumer JR, Haller JR, et al. Osseointegrated implants: A comparative study of bone thickness in four vascularized bone flaps. Plast Reconstr Surg 1993 Sep;92:(3): 449-455. PMID: 8341743.

8. Apinhasmit W, Sinpitaksakul P, Chompoopong S. Anatomical considerations of the Thai fibula used as a fibula osteocutaneous free flap in mandibular reconstruction and dental implant placement. J Med Assoc Thai. 2012 Apr; 95(4): 561-8. PMID: 22612012.

9. Matsuura M, Ohno K, Michi K, Egawa K, Takiguchi R. Clinicoanatomic examination of the fibula: anatomic basis for dental implant placement. Int J Oral Maxillofac Implants. 1999 Nov-Dec 14(6): 879-884. PMID: 10612927.

10.Teoh KH, Huryn JM, Patel S, Halpern J, Tunick S, Wong HB, et al. Implant prosthodontic rehabilitation of fibula free-flap reconstructed mandibles: a Memorial Sloan-Kettering Cancer Center review of prognostic factors and implant outcomes. Int J Oral Maxillofac Implants. 2005 Sep-Oct; 20(5):738-46. PMID: 16274148

11.Anne-Gaelle B, Samuel S, Julie B, Renaud L, Pierre B. Dental implant placement afte mandibular reconstruction by microvascular free fibula flap: current knowledge and remaining questions. Oral Oncol. 2011 Dec; 47(12):1099-104. Epub 2011 Aug 27. DOI: 10.1016/j. oraloncology.2011.07.016. PMID: 21873106.

12.Cho-Lee GY, Naval-Gías L, Martos-Díaz PL, González-García R, Rodríguez-Campo FJ. Vertical distraction osteogenesis of a free vascularized fibula flap in a reconstructed hemimandible for mandibular reconstruction and optimization of the implant prosthetic rehabilitation. Report of a case. Med Oral Patol Oral Cir Bucal. 2011 Jan 1;16(1):e74-8. PMID: 20711151. 